\title{
Government Success in Partnerships: The USDA-ARS Areawide Ecologically Based Invasive Annual Grass Management Program
}

\author{
By Brenda Smith and Roger L. Sheley
}

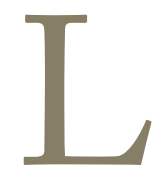

ong-term research about complicated pest management issues creates incremental knowledge that systematically solves problems. But once knowledge is well-enough advanced to dramatically improve the success of pest management, it is of little value unless that knowledge and technology are transferred to the intended users. Furthermore, the implementation of such technologies on a field-by-field level will have little impact on pest issues that cross regions, states, and sometimes countries. Since the mid-1990s, the US Department of Agriculture-Agricultural Research Service (USDAARS) has funded an Areawide Pest Management program to address both of these issues.

\section{What is an USDA-ARS Areawide Program?}

Areawide pest management is a strategy that has evolved from Integrated Pest Management (IPM). Whereas IPM is generally used on individual fields, an Areawide program extends IPM concepts over a large geographical area in a coordinated manner to maintain the target pest below economically damaging levels, while minimizing economic, health, and environmental risk. ${ }^{1}$ In addition to having effective technologies to address the pest management issue, the success of Areawide projects depends on an organized and coordinated attack on pest populations. ${ }^{1}$ Properly implemented, the methodology can significantly reduce and prevent the reoccurrence of major pest outbreaks, providing a more permanent management solution.

The USDA-ARS Areawide Pest Management program was initiated in the early 1990s when the USDA IPM working group formed a partnership framework for a national Areawide pest management initiative. Partners in Areawide projects come together from federal, state, and private entities. The first Areawide project was funded under this partnership framework in 1994 against codling moth (Cydia pomonella) in orchards in the northwest United States. ${ }^{1}$ The goal of this project was to reduce pesticide use, normally up to six applications per year, against codling moths in apple and pear orchards in Washington. A key to success of this project was grower participation. The project was initiated at five sites, involved 68 participants, and encompassed a total of 3,000 acres of orchards. As of 2008 more than 100,000 acres in three states use the integrated pest management strategies for codling moth developed from this program that has resulted in up to an $80 \%$ reduction in pesticide use. ${ }^{2}$

By 2007, the USDA-ARS Areawide program funded nine projects to provide long-term solutions to effectively manage serious economic agronomic pests. All of these projects met or exceeded goals to reduce pesticide use and have been widely supported from researchers to producers, with several receiving national awards. Two of these projects focused on limiting the spread of the invasive plants leafy spurge (Euphorbia esula) and melaleuca (Melaleuca quinquenervia). For the leafy spurge project, partners successfully integrated biocontrol, multispecies grazing, and herbicide applications to demonstrate how to keep leafy spurge at economically manageable levels, ${ }^{2}$ whereas reductions in the presence and spread of melaleuca in the Everglades was mainly achieved by implementing biological control. The impacts of these two programs are still being realized.

There are no specific protocols for Areawide projects, but all the projects include assessment, landscape demonstration areas, research, and education components. Once an Areawide project has been awarded, these components are implemented in three phases: 1) initiating research and installing demonstration, 2) creating and delivering outreach and technology transfer, and 3) ensuring long-term adoption.

In 2008, the USDA Areawide project for ecologically based invasive plant management (EBIPM) for invasive annual grasses in the Great Basin was funded to catalyze longterm sustainable management of ecosystems threatened and dominated primarily by cheatgrass and medusahead. In this article we will provide an overview of the annual grass issues 


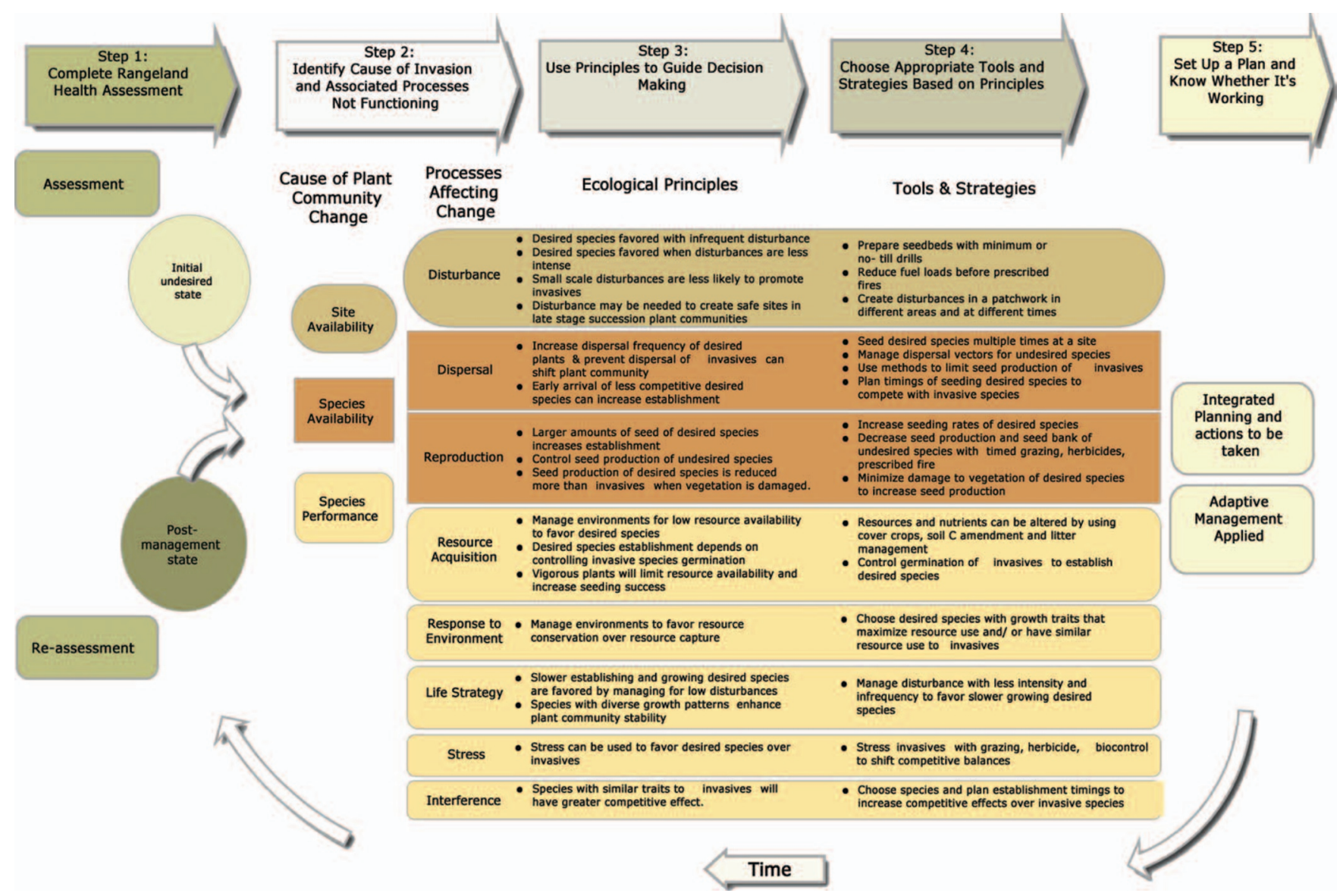

Figure 1. The ecologically based invasive plant management (EBIPM) model is a decision-thought process to help land managers develop integrated solutions to managing invasive annual grasses.

that led to the Areawide EBIPM project, outline the decision framework that is the basis for the project, describe the partnerships that have led to the success of the project, and describe products and outcomes of the project that have accelerated successful management of invasive annual grasses.

\section{A Storm Has Been Brewing for Some Time on Our Rangelands}

The invasion of annual grasses, primarily cheatgrass and medusahead, are creating catastrophic conditions on western rangelands. The massive acreages infested with these grasses reverberate through rural western communities, affecting all parts of the economy. The Great Basin ecosystem is a 200,000-square-mile intermontane plateau covering much of Nevada, over half of Utah, and parts of California, Idaho, Oregon, and Wyoming. With a conservative estimate of at least 130 million acres of the Great Basin infested with annual grasses and that number increasing rapidly, the permanent conversion of a once-diverse landscape to one limited to invasive grasses is a real concern. This conversion has many major negative impacts on ecosystems, associated wildlife, and human welfare and health. Rural areas are hard-hit economically as the decline in healthy and productive land intensifies throughout the community, when ranching and agriculture in general become marginally profitable. Heavy loads of fine, dry fuel promote frequent, dangerous, and harmful fires. Cheatgrass infestations increase the frequency of major rangeland fires to every three years from every 60 years.

Ultimately, the risk is permanently losing millions of acres of once productive habitat to vast monocultures of these grasses. Ecosystem functioning collapses with a lack of biodiversity when monocultures of this magnitude take over landscapes. Hydrologic and nutrient cycling is severely compromised, setting up situations for extreme soil losses to occur. Once ecosystems have been severely degraded, it is extremely difficult to impossible to restore and revegetate; some estimates of success are as low as $5 \% .^{3}$

\section{New Knowledge for Managing Rangeland: The EBIPM Decision Framework}

On landscapes degraded by invasive plants, repairing the ecological processes is critical to correcting the cause of invasion rather than continuously and periodically treating the symptoms. The need for an ecological framework from which to base our decision making for rangeland management and, specifically with invasive plants, is substantial and has been, until recently, largely unmet. ${ }^{4}$ In the early 1990s, Sheley and his collaborators ${ }^{5}$ advanced a successional management 


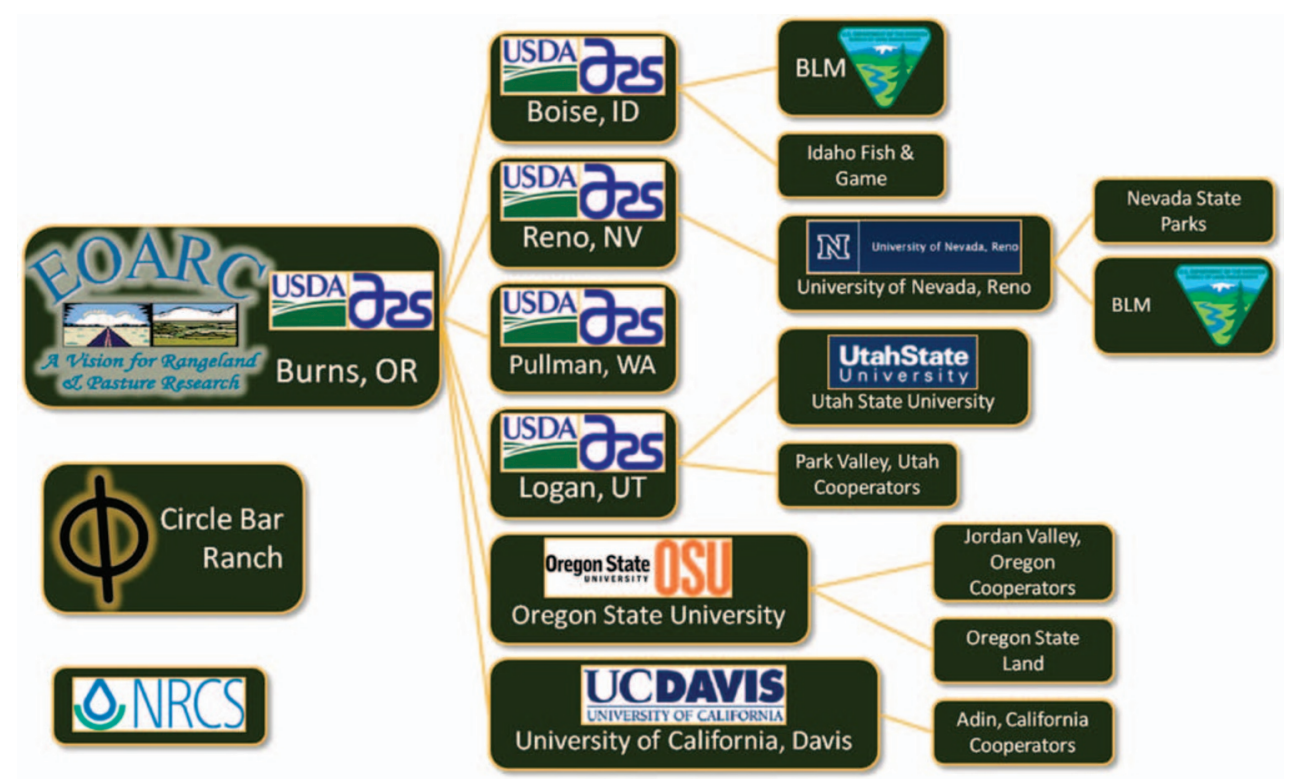

Figure 2. The Areawide project collaborators are from public and private entities throughout a five-state region in the Great Basin.

process-oriented framework that addressed repairing the ecological processes as the cause of invasion. The basis for a successional management model is in the three general causes of succession (site availability, species availability, and species performance), the ecological processes controlling these causes, and the factors modifying these processes. ${ }^{6}$ One of the crucial ideas of EBIPM is that it provides a mechanism for land managers to focus on finding the actual ecological causes of these infestations so they can stop treating the symptoms, the annual grass, and develop treatments to repair ecological processes not functioning in these ecosystems.

In recent years, the EBIPM framework has been arranged in a step-by-step structure to address land managers' need for clarity and usefulness. Managers can adopt the five-step EBIPM model to design, implement, and test science-based solutions to land management problems (Fig. 1). When tested, in two of three cases, using the framework has dramatically improved the outcome of management. Since this early work, substantial research has provided a set of ecological principles that managers can use to guide their strategies and choices of tools that can alter the ecological processes to favor desired plants and disfavor undesired ones.

The EBIPM decision model was developed with a logical, five-step program to overcome barriers to its adoption. Framed in this manner, the model is useful to land managers dealing with the challenges of invasive plants. In the first step, managers complete a Rangeland Health Assessment, and the information collected in this first step is collated in an EBIPM worksheet so that the ecological processes in disrepair emerge. In the second step, managers use the information gathered from the Rangeland Health Assessment to identify the causes of succession and associated processes that have lead to the invasion. The EBIPM model provides the ecological principles that are used in step three to guide decision making and link the ecological processes to the tools and strategies to repair the underlying causes of invasion. In step four, the tools and strategies are outlined for a program to begin managing the invasive grasses. Finally, in step five, adaptive management is incorporated into the planning process and development of a plan. This model forms the overarching basis for the EBIPM project.

\section{Successful Partnerships: A Key to Successful Programs}

When the proposal for the Areawide project for EBIPM of invasive annual grasses was granted, ARS leadership recognized that the long-term success of the project would be dependent on forming a number of collaborative partnerships. This Areawide project is centered at the USDA-ARS Eastern Oregon Agricultural Research Station in Burns, Oregon, where Dr. Roger Sheley is the project director. Additionally, there are five major "hubs" for the Areawide project, and each hub has developed extensive partnerships with university researchers, ARS scientists, land managers, and producers at each location. These "hubs" are located in Boise, Idaho; Logan, Utah; northern Nevada; northern California; and Jordan Valley, Oregon. In total, there are more than 20 principal investigators and/or senior project associates that are responsible for the development of demonstration, research, and outreach for this project (Fig. 2).

The successes of the project to date are clearly a result of a very effective collaborative atmosphere. Significant preplanning prior to submitting the proposal for the Areawide project greatly facilitated buy-in and ownership from all the stakeholders involved. We believe these pre-discussions were a key element in getting the project off to a great start and kept any encountered difficulties to minor inconveniences. 
Table 1. A broad range of educational materials have been produced as part of the technology transfer for the Areawide project. Emphasis has been placed on a series of step-by-step decision-support tools

\section{Areawide Ecologically Based Invasive Plant Management (EBIPM) products*}

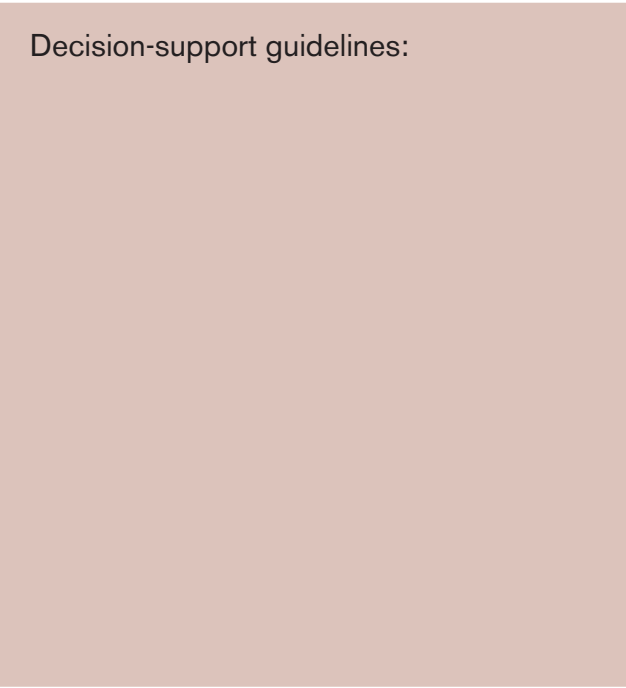

Instructional DVDs/videos:

Learning tools:

Fact sheets and bulletins:

Web site and curriculum:

EBIPM training:
EBIPM Assessment Guidelines

Researching Cultivation History

Applying Ecologically Based Invasive Plant Management

Ecological Principles for Invasive Plant Management

Grazing Invasive Annual Grasses: The Green and Brown Guide

Establishing a Weed Prevention Area

Revegetation Guidelines for the Great Basin

Adaptive Management for Invasive Annual Grasses

Implementing EBIPM: in the Field

Implementing EBIPM: Science-Driven Invasive Plant Management

A Working Ranch with an Effective Medusahead Management Program

2011 and 2012 EBIPM calendars

The Weed Wheel

A Working Ranch with an Effective Medusahead Management Program

Ranching, Invasive Annual Grasses, and the Economics of Wildfire in the Great Basin

Ranch Annual Grass Management Program

www.ebipm.org

High school curriculum

University/Land manager curriculum

2008 Course: Burns, Oregon

2009 Field School: Circle Bar Ranch, Mitchell, Oregon

2010 Field School: Boise Skate Park and Demonstration Sites, Idaho

2011 Field School: Park Valley Demonstration Sites, Utah 


\section{Table 1. Continued}

\section{Areawide Ecologically Based Invasive Plant Management (EBIPM) products*}

\begin{tabular}{|c|c|}
\hline \multirow[t]{7}{*}{ Journal articles and textbook: } & Invasive Plant Science and Management (10) \\
\hline & Plant Ecology (4) \\
\hline & Rangeland Ecology \& Management (4) \\
\hline & Rangelands (3) \\
\hline & $\begin{array}{l}\text { CABI Book: Invasive Plant Ecology and Management: Linking Processes to } \\
\text { Practice }\end{array}$ \\
\hline & Journal of Arid Environments (2) \\
\hline & Others (5) \\
\hline \multirow[t]{5}{*}{ Theses: } & Hirsch, M. C. 2011 \\
\hline & Fowers, B. 2011 \\
\hline & Mangla, S. 2010 \\
\hline & Christensen, S. 2011 \\
\hline & Kartchner, H. 2012 \\
\hline
\end{tabular}

The project has gone exceedingly well and this is in a large part to the extensive pre-planning efforts. In the following section we will outline the chronological development of the Areawide EBIPM project.

\section{Implementing EBIPM Through the Areawide Project}

\section{Phase 1: Initialing and Installing Demonstration}

Once the project was underway in 2008, the first order of business was organizing and implementing landscape-scale demonstration areas in each of our selected "hub" sites. During this phase, it was critical to develop partnerships with private producers and land managers who were facing the challenge of invasive annual grass infestations. The demonstration areas were designed to test the application of EBIPM for invasive annual grass management and have, in fact, become the cornerstone for our outreach and education efforts as well. The key partnerships formed with stakeholders during this time have been a central positive feature for all the subsequent programs of the project.
In addition to the demonstration areas, numerous gap-filling research experiments were designed and initiated to assess the extent and impacts of cheatgrass and medusahead on the ecosystems they invade as well as develop more definitive science-based solutions to unanswered questions relating to complex climate and species interactions. Another important component of the project has been to assess the economic impacts of invasive annual grass infestations and to estimate the changes in economic benefits of implementing EBIPM programs. The economic analyses have been conducted with our partners at University of Nevada-Reno since the inception of the project.

\section{Phase 2: Creating and Delivering Outreach and} Technology Transfer

Successful Areawide projects, where widespread adoption of programs occurs, have always included well-developed outreach and education technology transfer. A strong emphasis for education and outreach was built into this project from the beginning by establishing an "outreach-education coordinator" position. Our goal in phase two of the project has been to 


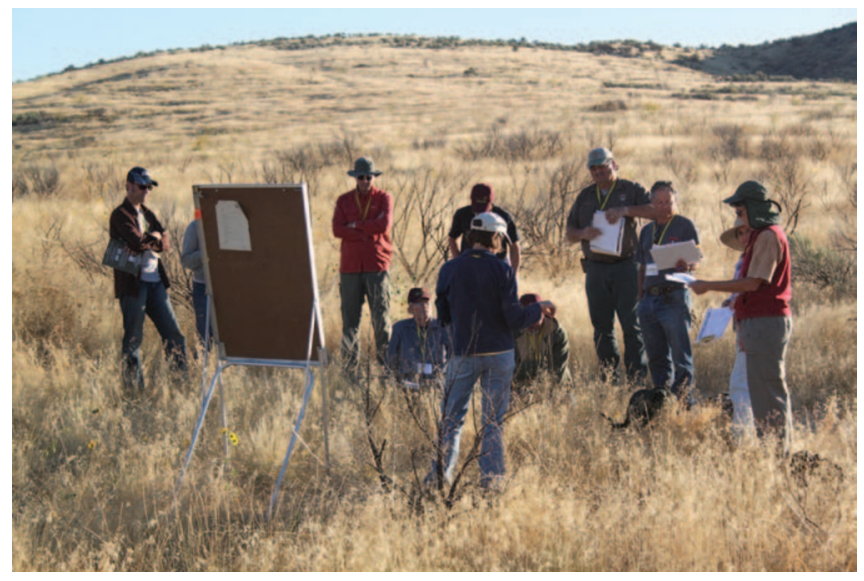

Figure 3. Participants working on their ecologically based invasive plant management (EBIPM) management plan for cheatgrass in a recently burned over landscape during the EBIPM Field School held in Boise, Idaho, September 2010. More than 80 land managers were in attendance.

introduce, transfer, and promote the adoption of EBIPM to improve the overall management of invasive annual grasses. To reach these goals, we have developed, and continue to develop, user-support decision tools that are helpful to land managers as they begin implementing EBIPM planning (Table 1).

We began planning an outreach and education program that could best be described as using "direct marketing" strategies. It was important to gain an online presence early on with the project, and our Web site is designed as a one-stop shop for all things related to invasive annual grass and EBIPM. All publications and educational materials developed as part of this project are available at this Web site. Staying fresh, current, and interactive are all important details in increasing traffic to our Web site. Now in year three of the project, our Web site typically gets 350-400 views per month.

Even with the enormous popularity of the internet, significant effort was and is devoted to developing written decision-support guidelines and instructional videos. These decision tools collectively comprise a complete EBIPM approach to assess and manage land threatened or dominated by cheatgrass and medusahead. They are available in multiple formats as pdf files or videos online on the Web site, but we believe that having the printed copies available for individual order and all the materials organized into a complete EBIPM Resource Handbook is a key to gaining widespread awareness of the EBIPM process. All EBIPM products are used as part of educational events that are sponsored by Areawide project partners.

A number of educational opportunities were developed and are available to land managers and producers. This is where our demonstration areas have been fully utilized. A cornerstone in achieving our educational successes has been our an-

www.ebipm.org nual EBIPM field school that rotates annually to a different demonstration area (Fig. 3). The field school concept has been to take our core ideas of EBIPM into the field to learn by doing. We have received excellent feedback from our participants in the field school, including the following comments:

- "I think the framework of the model is very useful as well as understanding the categories of plant community change."

- "Real world examples and real world sites to visit where these principles can be applied. Working in a group was nice; it was good to hear different people's strategies and ideas."

- "Applying the principles of EBIPM out in the field was the most useful. The handbook \& materials are great to have as references. I will rely on them a lot. Thanks, a great course."

An additional facet of the education program strategy is the development of curricula for high school and college courses and for land managers. These curricula put into place an integrated decision framework for transforming the way we conduct rangeland management. Currently, at least eight universities have indicated they have adopted at least parts of the EBIPM model into their curriculum in several different classes. The curricula are available to educators on our EBIPM Web site.

We have also gained significant momentum increasing awareness for weed prevention areas by coordinating with Utah State University and a local coordinated weed management area (CWMA). The CWMA was concerned about spreading infestations of medusahead in their watershed, and they employed a number of strategies to get a handle on infestations in an area of Utah that has relatively low medusahead populations. A decision-support tool based on the experiences of this group, Establishing a Weed Prevention Area, details the steps a community can take to zone in on a community-based program to prevent infestations of any invasive plant from impacting a watershed.

\section{Phase 3: Ensuring Long-Term Adoption}

Developing the Web site for EBIPM was part of Phase 2 in creating awareness of the program but it is also a means to ensuring long-term adoption of EBIPM well beyond the time when final funds for the project are dispersed. Our Web site emphasizes scientific information in user-friendly formats. When we have good research and good solutions to management problems associated with invasive grasses, we believe it is important that our information is packaged well into useful formats. These efforts in designing a complete product in a number of different communication mediums have paid off in terms of increasing the adoption rates of EBIPM. We can be assured of the long-term adoption of EBIPM by land managers and producers with all the programs we have strategically put into place. A strong emphasis on printed decisionsupport tools, education, and online presences are all designed 
for EBIPM to be carried out to improve rangeland conditions throughout the Great Basin. An internet presence has helped and will continue to help provide the widest dissemination possible of the EBIPM program and is the basis for getting as many EBIPM efforts started as possible. Our goal is to get as much interest as possible generated by land managers and then make sure they have the tools and decision-support materials so they can successfully implement EBIPM on their land.

\section{USDA-ARS Areawide Project Impacts}

As we evaluate the impacts of the Areawide EBIPM project over the past four years, we find the inroads made to more ecologically based plant management are widespread. The indications are that EBIPM is being adopted and is changing the way we do business on invasive annual grass management on our western rangelands. Determining the rate of adoption is a fairly complex problem and requires a fair amount of assumptions. However, from exit surveys at our workshops, we have over $90 \%$ agreement from our participants to the statement "The EBIPM framework will help improve my decision making." A land manager just has to adopt one idea or principle from EBIPM to then begin to impact the acreage they manage. We use this information in figuring the impacts listed below. Overall, we believe our estimates of impacts are very conservative due to the complexities in collecting data of EBIPM adoption rates.

This management change is occurring because of a wellchoreographed program where research has contributed more than 35 refereed journal articles accepted or submitted to date with many more in the works. To date, five theses have been completed where EBIPM was central to the research conducted. We have eight user-support guidelines and more than 7,000 have been distributed or requested as of this writing. Three videos have been produced to introduce and instruct managers on how to implement EBIPM, and more than 1,500 have been distributed. A large education effort has directly reached over 250 land managers at our last three annual field schools and easily more than 2,000 managers at various workshops and conference presentations. All of our products are available as an inclusive EBIPM Resource Guide. Important to the success of the program is reaching broad audiences, and we have achieved this through an internet presence, development of a curriculum, and education through a number of venues and our decision-support products.

Where we stand now, this multiagency, multistate partnership has systematically facilitated the adoption of sciencebased methods for managing ecosystems invaded or threatened by invasive annual grasses throughout the Great Basin and surrounding ecosystems.

The Areawide EBIPM project has: 1) advanced the use of science-based decision making in range and wild land management by providing an ecologically based decision-support system for producers and managers; 2) improved our knowledge base by linking rangeland assessment procedures to management by providing ecological data necessary in making

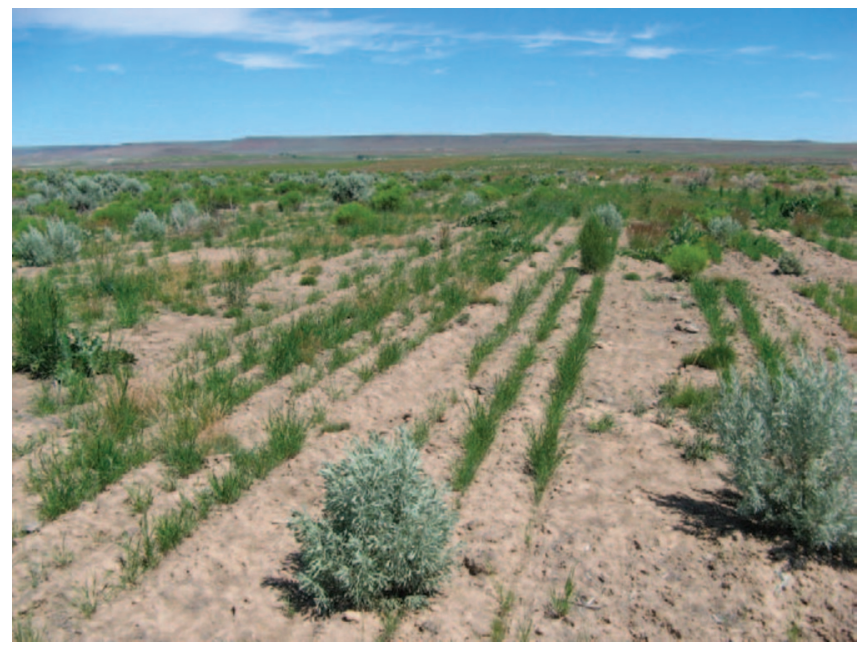

Figure 4. One of the landscape-scale demonstration sites in Jordan Valley, Oregon in June 2011, two years after initiating ecologically based invasive plant management (EBIPM) management. The competitive balance has shifted from the annual grasses to the establishing perennial grasses, primarily crested wheatgrass (Agropyron cristatum $\times$ desertorum 'Hycrest').

science-based decisions; 3) provided new principles for management; and 4) potentially prevented invasion on millions of acres as a results of implementation of Weed Prevention Areas.

Ultimately, the true test of impacts of a program such as this is seeing results on the ground (Fig. 4). We estimate that, as a result of this project's activity to date, we have directly affected positive land management on more than 500,000 acres of rangeland, and indirectly impacted more than 2.5 million acres.

\section{Reasons for the Areawide EBIPM Project \\ Success}

When we reflect on what has made the Areawide EBIPM project a success, overall we can point to "big picture" vision and strong leadership among the principal investigators. The entire team has been clear about what needs to be accomplished through careful development and up-front planning for research and education strategies. Our successes have also been due to having producers, our stakeholders, directly involved in the project from the beginning, even before the proposal was submitted, gaining their buy-in and ownership and keeping them up to date with regular communications. There has also been at the core of the Areawide EBIPM team the commitment to providing full-service support to land managers implementing EBIPM.

Maintaining good communication through a number of formal and informal avenues has helped the project stay on track; when people are abreast of the activities, they are more inclined to stay involved. Regular conference calls with all the project collaborators have occurred throughout the life of the project. The project director and outreach coordinator make frequent visits to our project demonstration "hubs" in support of the work being conducted in each of these areas. On the whole, the project has positive forward mo- 
mentum, keeping the enthusiasm up among all of our partners. The project enjoys a strong collaborative atmosphere, and collaboration works because the teams want to be a part of something advancing rangeland management throughout the West. From momentum created by the Areawide EBIPM project, we have established a new framework of science-based solutions to manage invasive plants. This Areawide project is clearly an effective example of how government partnerships can lead and advance positive changes to our land management practices.

\section{Acknowledgments}

The authors wish to thank the entire EBIPM team for their collaborative efforts in creating this successful project. Without their dedication, this project would not have been possible.

\section{References}

1. Faust, R. M. 2008. General introduction to Areawide Pest Management. In: O. Koul, G. Cuperus, and N. Elliott [EDs.]. Areawide Pest Management theory and implementation. Cambridge, MA, USA: CAB International. p. 1-14.
2. Stelljes, K. B. 2001. No codling for this moth. Agricultural Research Magazine 49(11):17.

3. Briske, D. D. [ED.]. 2011. Conservation benefits of rangeland practices: assessment, recommendations, and knowledge gaps. Lawrence, KS, USA: USDA-NRCS. 429 p.

4. Sheley, R., T. J. Svejcar, and B. D. Maxwell. 1996. A theoretical framework for developing successional weed management strategies on rangeland. Weed Technology 10:766-773.

5. Sheley, R., J. James, B. Smith, And E. Vasquez. 2010. Applying ecologically-based invasive plant management. Rangeland Ecology \& Management 63:605-613.

6. Pickett, S. T. A., S. L. Collins, and J. J. Armesto. 1987. Models, mechanisms and pathways of succession. Botanical Review 53:335-371.

Authors are Research Agronomist, brenda.smith@ars.usda.gov (Smith) and Rangeland Ecologist (Sheley), USDA-ARS Eastern Oregon Agricultural Research Center, 67826-A Hwy 205, Burns, OR 97720, USA. 